\title{
CATADOR DE MATERIAL RECICLÁVEL: UMA PROFISSÃO PARA ALÉM DA SOBREVIVÊNCIA?
}

\author{
Luiza Ferreira Rezende de Medeiros \\ Kátia Barbosa Macêdo \\ Universidade Católica de Goiás
}

\begin{abstract}
RESUMO: $\mathrm{O}$ artigo apresenta resultados de uma pesquisa que objetivou investigar as relações de trabalho entre catadores de materiais recicláveis e organizações de reciclagem dos materiais coletados. Os catadores atuam no município de Goiânia. A reciclagem de lixo urbano figura como atividade emergente após movimentos ambientalistas e de preservação ambiental. Embora gere vantagens ambientais indiscutíveis, sobressaem os aspectos econômicos. A catação de materiais recicláveis constitui, para muitos trabalhadores, única forma de garantir sobrevivência e possibilidade de inclusão num mercado de trabalho excludente. Essa pesquisa investigou como os catadores percebem suas relações de trabalho, as condições em que desempenham suas funções e as práticas do trabalho em cooperativas de reciclagem. Utilizou-se entrevistas com 10 catadores, que foram tratadas pela análise de conteúdo. Os dados revelaram relações de trabalho precárias e informais entre catadores e organizações de reciclagem. Os trabalhadores são expostos à periculosidade, vítimas de preconceitos e estigmas e excluídos de alguns ambientes sociais.
\end{abstract}

PALAVRAS-CHAVE: catador de material reciclável; precarização das relações de trabalho; inclusão social.

\section{RECYCLED GARBAGE PICKERS - A PROFESSION BEYOND SURVIVAL?}

ABSTRACT: The article presents results of a research that investigated the work relations between recycled garbage pickers working in Goiânia and organizations that recycle such materials. The recycling of urban garbage figure as an emergent activity after environmentalist movements and environment preservation. Although it generates unquestionable environmental advantages, the economic benefits excel. Collecting garbage, to many workers, is the only way of guaranteing survival and inclusion in the excluding market. This research investigated the way garbage pickers understand their work relations, under what conditions perform their functions, and the work practices in garbage picking cooperatives. Ten garbage pickers were interviewed and data analyzed by content analysis. Data showed precarious and informal work relations between garbage pickers and garbage picking cooperatives. The workers are exposed to danger, victims of prejudice and stigma, and excluded from some social places.

KEYWORDS: recycled garbage picker; precarious work relations; social inclusion.

\section{Introdução}

\section{As transformações do mundo do trabalho em um contexto globalizado}

Pode-se falar do trabalho humano desde os primórdios da humanidade, contudo, Antunes (1995) esclarece que embora seja "ineliminável" da própria condição humana, o trabalho não é um objeto natural, mas uma ação essencial para estabelecer as relações entre o homem e a natureza, e entre as sociedades e a natureza.

Marinho (2005) acrescenta que o conceito e o lugar que o trabalho ocupa em determinado contexto histórico implica a representação que se faz daquele que trabalha, bem como daquele que não trabalha e, portando, do próprio conceito de trabalho.

Assim, as concepções sociais, econômicas e políticas produzidas em diferentes épocas são expressas em modalidades distintas de relações de trabalho. Dessa forma, o modelo de sociedade característico do século XX, e que ainda permanece no séc. XXI, foi construído tendo como elemento essencial o trabalho, porém não qualquer tipo de trabalho, mas, especificamente, o trabalho assalariado, típico do sistema capitalista que emerge no final do séc. XVII.

Segundo Codo (1993), a palavra trabalho origina-se do latim, tripalium, trabicula que significava instrumento de tortura, apontando para a idéia de sofrimento ou de castigo. Já entre os gregos, a palavra ponos significava trabalho, e teria a mesma raiz da palavra latina poena, também uma referência ao sofrimento. No português, a palavra pena, tem em sua origem o duplo sentido de punição e sofrimento. Ainda hoje, a palavra conserva o mesmo sentido: todo esforço que fatiga, diz-se que é penoso.

A relação homem-trabalho, elemento estruturante do intercâmbio social entre os homens e a natureza, expressa na dimensão transformadora do trabalho, foi, no século XIX, assim apreendida por Marx (1978):

Antes de tudo, o trabalho é um processo entre o homem e a natureza, um processo em que o homem, por sua própria ação, media, regula e controla o 
seu metabolismo com a Natureza. Ele mesmo se defronta com a matéria natural como uma força natural. Ele põe em movimento as forças naturais pertecentes à sua corporalidade, braços, pernas, cabeça e mãos, a fim de apropriar-se da matéria natural numa forma útil para sua própria vida. A atuar, por meio desse movimento sobre a Natureza externa a ele, e ao modi-ficá-la, ele modifica a sua própria natureza (p.148).

Ao dizer que o trabalho cria o homem, e, por força da dialética, que o homem cria a si mesmo pelo trabalho, Marx provocou uma reflexão sobre o que era o trabalho e evocou sua função mediadora na relação entre o homem e a natureza. Através do trabalho, o homem superou sua condição de ser natural e se converteu em ser social.

É moderna a idéia de que o homem se faz a si mesmo e se eleva como ser humano por meio do trabalho, transformando o mundo material. E a essa forma de pensar acrescenta-se a consolidação de um aparato legal e a aparente conversão de trabalho social em trabalho assalariado.

Institui-se o contrato de trabalho como a expressão jurídica para definir a relação econômica de compra e venda de trabalho. Segundo Codo (1993) "por meio do contrato de trabalho, um trabalhador se compromete a trabalhar durante certo período, o que configura a jornada de trabalho em troca de um salário" (p.132).

Na primeira metade do século XX, vivenciou-se em diversos países ocidentais de economia avançada a concessão de novos e abrangentes direitos sociais. Entre eles, a garantia do emprego como um direito social.

De maneira sintética, Marinho (2005) afirma que "o trabalho passou a ser o 'sentido da vida', possibilidade de enriquecimento futuro, e, para além do problema da sobrevivência, ainda que heterônomo, é proclamado como virtude" (Marinho, 2005, p.27).

Contudo, as mudanças estruturais, tecnológicas e econômicas que marcaram as últimas décadas, desde o final do século XX, resultaram em mudanças na configuração do "mundo do trabalho".

Nessa pesquisa, entende-se que o trabalho ocupa um lugar central na vida de quem o realiza. Para tanto, são enfocados dois fatores: o fato de ele ser um meio de sobrevivência e o tempo de vida a ele dedicado. $\mathrm{O}$ trabalho, além de ser um meio de subsistência, também é um meio de integração social, pois possibilita o relacionamento entre pessoas, a inclusão social e o sentimento de pertencer a um grupo. Assim, explica Dejours (1987), o trabalho significa para o trabalhador uma forma de afirmar sua identidade por meio de atribuições individuais inseridas por ele na realização da tarefa.

Pode-se concluir que o trabalho é elemento integrante da vida das pessoas, seja ou não na sua forma assalariada, pois vive-se em uma sociedade em que é o trabalho que possibilita a construção de uma identidade, não só profissional como também pessoal, além de ser meio de reconhecimento e de valorização social. O trabalho tem um significado essencial no universo da sociabilidade humana, ele não é apenas meio de vida, ele forma a identidade da pessoa e a sua profissão caracteriza o seu modo de vida.

\section{A precarização das relações de trabalho}

Marinho (2005) afirma que para abordar as transformações no denominado "mundo do trabalho" tem-se que considerar o processo de reestruturação produtiva, pois "as relações de trabalho e as formas de organização dos trabalhadores estão profundamente relacionadas com as transformações da produção e do mercado" (p.24). Dessa forma, na primeira década dos anos 2000, estas transformações consolidam-se e as conseqüências da reestruturação produtiva se delineiam com mais nitidez.

Segundo Antunes (1995), Heloani (2003) e Borges e Goulart (2002), em uma explicação sucinta, o Taylorismo/ Fordismo, datado do início do século XX, baseava-se na produção de mercadoria em massa, que se estruturava em uma produção mais homogeneizada e fortemente verticalizada. Esse padrão produtivo teve como elementos fundamentais: o trabalho parcelar e fragmentado e a decomposição das tarefas, que reduziam a ação em suas operações mínimas; a separação entre execução e planejamento; o aumento do controle sobre o trabalhador; a cronometragem de cada movimento do operário na execução das operações e a rotinização do trabalho.

Uma situação emblemática resultante dessa reestruturação produtiva seria a precarização das condições e relações de trabalho e o desemprego em sua forma estrutural.

Sobre a precarização das condições de trabalho, Mattoso (1999) assim define:

Aumento do caráter precário das condições de trabalho, com a ampliação do trabalho assalariado sem carteira e do trabalho independente (por conta própria). Esta precarização pode ser identificada pelo aumento do trabalho por tempo determinado, sem renda fixa, em tempo parcial, enfim, pelo que se costuma chamar de bico. Em geral, a precarização é identificada com a ausência de contribuição à Previdência Social e, portanto, sem direito a aposentadoria. O processo de deterioração das relações de trabalho, com a ampliação da desregulamentação dos contratos temporários, de falsas cooperativas de trabalho, de contratos por empresa ou mesmo unilaterais (p.8).

A precariedade refere-se ao trabalho mal remunerado, pouco reconhecido, e que provoca um sentimento de inutilidade no trabalhador. Refere-se ainda à instabilidade do emprego, à ameaça do desemprego, à restrição dos direi- 
tos sociais e à falta de perspectivas de crescimento profissional, manifestada tanto em relação ao setor informal, quanto para a classe trabalhadora em geral.

Segundo Piccinini (2004), a difusão das formas precárias está ligada à flexibilidade quantitativa, à redução de custos pelo recurso a vínculos contratuais instáveis e à substituição de contratos de trabalho por contratos comerciais. Ela cita como tipos de flexibilidade quantitativa: a terceirização e subcontratação, trabalho em domicílio, rede de empresas, cooperativas de trabalho, trabalho temporário, trabalho em tempo parcial, trabalho em tempo compartilhado, suspensão temporária do contrato de trabalho e estágios. Segundo Antunes (1995), essa precarização do trabalho está em plena sintonia com o modo de produção capitalista.

Conclui-se que, atualmente, há uma crise do trabalho assalariado nos moldes típicos do sistema capitalista, expressa nas seguintes formas: aumento do desemprego estrutural e precarização do trabalho, exclusão de trabalhadores do mercado formal de trabalho e exclusão do convívio social.

Uma análise equivocada desse contexto leva muitos autores a proclamarem o adeus ao trabalho.

Dejours (1999) evidencia que as consequiências psicossociais advindas da crise atual do trabalho assalariado são perversas, pois atacam os alicerces da identidade do ser humano. Ele distingue a relação entre sofrimento e emprego, e sofrimento e trabalho. A primeira está ligada à crise do trabalho assalariado e ao desempregado, e a segunda diz respeito aos trabalhadores que continuam a trabalhar. Assim, Dejours (1999) esclarece que também existe o sofrimento dos que trabalham, pois:

Existe o sofrimento dos que temem não satisfazer, não estar à altura das imposições da organização do trabalho: imposições de horário, de ritmo, de formação, de informação, de aprendizagem, de nível de instrução e de diploma, de experiência, de rapidez de aquisição de conhecimentos teóricos e práticos e de adaptação à "cultura" ou à ideologia da empresa, às exigências do mercado, às relações com os clientes, os particulares ou o público, etc. (p.98).

Conforme Antunes (1995), Mattoso (1999) e Souto de Oliveira (2004), fazem parte das transformações no mundo do trabalho: o declínio do setor secundário na absorção de mão-de-obra e a expansão do setor terciário; a retração do salário formal, flexibilização das relações contratuais de trabalho, redundando em perda ou subtração de direitos do trabalho e, conseqüientemente, num menor ou mesmo ausente grau de proteção social; as mudanças nos requerimentos feitos ao trabalhador, sob a égide da "empregabilidade", que se traduzem por maior grau de escolarização formal e por uma crescente exigência de atributos, tais como polivalência, autonomia, iniciativa e competitividade; a informalização e precarização das relações de trabalho; a manutenção/agravamento das desigualdades de rendimento e a dilatação das margens de pobreza.

\section{A exclusão social e a inclusão perversa: o caso dos catadores de lixo}

Partindo das transformações no mundo do trabalho explicitadas no tópico anterior, pode-se inferir que é crescente e expressivo o número de trabalhadores que se encontram sob condições que configuram exclusão social. Dessa forma, neste tópico buscar-se-á refletir sob o conceito de exclusão/inclusão de uma parcela de trabalhadores que tem como trabalho catar materiais recicláveis do lixo urbano.

O debate sobre o conceito de exclusão social, muito presente nas discussões contemporâneas foi, segundo Freitas (2005), elaborado em solo francês em meados dos anos 1970. Wanderley (1999) afirma que "atribui-se a René Le-noir a invenção dessa noção de exclusão em 1974" (Wan-derley, 1999, p.16).

Sawaia (1999) opta pela expressão dialética exclusão/ inclusão, superando uma visão dualista de incluídos X excluídos. Para a autora:

Ao optar pela expressão dialética exclusão/inclusão é para marcar que ambas não constituem categorias em si, cujo significado é dado por qualidades específicas invariantes, contidas em cada um dos termos, mas que são da mesma substância e formam um par indissociável, que se constitui na própria relação (p.108).

Para essa autora, exclusão pela inclusão não seria inadaptação, mas, ao contrário, é adaptação à exclusão social, a exclusão para se repor precisa ancorar-se no sentimento de pertencimento social e criar o sentimento de pertença ou inclusão nos seus sujeitos. Dessa forma, afirma a autora, "é no sujeito que se objetivam as várias formas de exclusão (...) é o indivíduo que sofre, porém, esse sofrimento não tem a gênese nele, e sim em intersubjetividades delineadas socialmente" (Sawaia, 1999, p.99).

Para Guareshi (1999), no entendimento da sociedade contemporânea, o conceito de exclusão é crucial, isso porque as transformações do mundo do trabalho, principalmente as advindas das transformações do modo de produção, modificaram o cenário das relações sociais até então vigentes.

Muitos autores abordam a inclusão social tomando como referência principal a situação de desemprego. Assim, estar desempregado significaria não estar integrado. Mas, o que dizer daqueles que trabalham sem, contudo, terem um emprego? Seria o desemprego o ponto de partida para a análise da inclusão/exclusão social de uma parcela de trabalhadores que desempenham trabalhos como a ca-tação de material reciclável? 
A adoção exclusiva desse ponto de partida levaria ao ofuscamento de artimanhas da exclusão social. Isso porque, por trás de formas aparentes de inclusão social, existem formas sutis de exclusão que conduzem a uma aparente inclusão, que camufla uma exclusão, entendida como inclusão perversa. Sendo assim pode-se concluir que não há exclusão antes de uma inclusão.

Conclui-se que, conforme Sposati (2002) e Sawaia (1999), a idéia de exclusão social supõe uma lógica que preside um padrão de relações em uma sociedade que, ao mesmo tempo, inclui e exclui por meio de um conjunto de valores que a orienta.

\section{A profissão de catador}

No Brasil, estima-se que o número de catadores de materiais recicláveis seja de aproximadamente 500.000 (quinhentos mil), estando 2/3 deles no Estado de São Paulo. Conforme dados da Companhia Municipal de Urbanização de Goiânia - COMURG, em Goiânia, no ano de 2004, foram identificados 506 catadores que coletam materiais recicláveis na cidade. Há indícios de que em Goiânia esse número seja bem maior, conforme elucidado em outros tópicos.

Birbeck (1978) denomina os catadores de "self-employed proletarians", pois, segundo o autor, o auto-emprego não passa de ilusão, pois os catadores se auto-empregam, mas na realidade eles vendem sua força de trabalho à indústria da reciclagem, sem contudo terem acesso à seguridade social do mundo do trabalho.

A rotina diária do catador é exaustiva e realizada em condições precárias, conforme afirma Magera (2003):

\begin{abstract}
Muitas vezes, ultrapassa doze horas ininterruptas; um trabalho exaustivo, visto as condições a que estes indivíduos se submetem, com seus carrinhos puxados pela tração humana, carregando por dia mais de 200 quilos de lixo (cerca de 4 toneladas por mês), e per-correndo mais de vinte quilômetros por dia, sendo, no final, muitas vezes explorados pelos donos dos depósitos de lixo (sucateiros) que, num gesto de paternalismo, trocam os resíduos coletados do dia por bebida alcoólica ou pagam-lhe um valor simbólico insuficiente para sua própria reprodução como catador de lixo (p.34).
\end{abstract}

Os catadores catam e separam do lixo o material reciclável numa quantidade que seja suficiente para vender. O comércio dos materiais recicláveis entre os catadores e as empresas de reciclagem geralmente passa pela mediação dos atravessadores, chamados de sucateiros.

Esses intermediários, os sucateiros, recebem o material coletado pelos catadores, pesam e estabelecem o preço a ser pago aos catadores. Em seus depósitos, os sucateiros vão acumulando os materiais prensando-os em fardos, até conseguirem uma quantidade que viabilize o transporte para as indústrias de reciclagem. Um dia de trabalho rende aos catadores de 2 a 5 reais dependendo da quantidade e do tipo de material que recolhem.

Para Carmo (2005), os catadores desconhecem completamente os aspectos que envolvem a logística do processo de reciclagem, desconhecimento muitas vezes atribuído ao baixo nível de escolaridade. Carmo (2005) e Magera (2003) concordam que esse pouco conhecimento do circuito da reciclagem é um forte impedimento para que catadores obtenham ganhos melhores nessa atividade.

Já para Viana (2000), a existência dos atravessadores pode ser explicada por dois fatores principais: primeiro, pela "dificuldade de locomoção" dos catadores de lixo para entregar o material nas indústrias de reciclagem e, segundo, pelas vantagens que esse sistema oferece às indústrias.

Dessa forma, concluem Leal et al. (2002) que o catador de material reciclável participa como elemento base de um processo produtivo bastante lucrativo, no entanto, paradoxalmente, trabalha em condições precárias, subumanas e não obtém ganho que lhe assegure uma sobrevivência digna.

Magera (2003), IPT (2003) e Miura (2004), relacionam o crescimento do número de catadores de materiais recicláveis com as crescentes exigências para o acesso ao mercado formal de trabalho e também ao aumento do desemprego. Para esses autores, alguns trabalhadores da catação constituem uma massa de desempregados que, por sua idade, condição social e baixa escolaridade, não encontram lugar no mercado formal de trabalho.

Embora a catação seja tal como a atividade de vendedor ambulante, realizada informalmente, a partir da década de 1980, os catadores começaram a se organizar em cooperativas ou associações, na busca pelo reconhecimento dessa atividade como profissão. Nos anos 1990, com o apoio de instituições não governamentais, foram promovidos encontros e reuniões em vários locais do país com essa finalidade. Novos parceiros foram incorporados, e o ano de 2001 culminou com a realização do " $1{ }^{\circ}$ Congresso Nacional de Catadores de Materiais Recicláveis e a $1^{\mathrm{a}}$ Marcha da População de Rua" (Magera, 2003, p.105). Com o fortalecimento dessas manifestações, criou-se o movimento nacional de catadores.

Dessa forma, os catadores estão construindo sua história e demarcando sua área de atuação, conquistando também seu reconhecimento como categoria profissional, oficializada na CBO - Classificação Brasileira de Ocupações, no ano de 2002.

Nessa classificação, os catadores de lixo são registrados pelo número 5192-05 e sua ocupação é descrita como catador de material reciclável. Segundo a descrição sumária de suas atividades na CBO, os catadores "catam, selecionam e vendem materiais recicláveis como papel, papelão e vi- 
dro, bem como materiais ferrosos e não ferrosos e outros materiais re-aproveitáveis" (www.ministeriodotrabalho. gov.br).

No ano de 2003, o Governo Federal criou o comitê de inclusão social de catadores de lixo. Dentre outras atribuições esse comitê deveria implantar projetos que visassem garantir condições dignas de vida e trabalho à população catadora de lixo, bem como apoiar a gestão e destinação adequada de resíduos sólidos nos municípios brasileiros.

Contudo, observa-se que os catadores desempenham suas atividades em condições precárias, sofrem preconceitos e possuem baixo reconhecimento do papel que representam na economia e no meio ambiente, embora tenham a profissão reconhecida e sejam resguardados por um comitê específico.

Para Miura (2004), o problema hoje não está em reconhecer legalmente o catador como um profissional, mas sim, em reconhecer seu direito às condições dignas de trabalho e de vida para além da perspectiva estrita da sobrevivência.

Segundo Migueles (2004), "para que a sociedade perceba o catador como 'um outro trabalhador qualquer' é preciso associar o trabalho de catação a significados positivos" (p.14).

Esses autores correlacionam o caráter excludente do trabalho do catador à semântica negativa do lixo, e que essa situação interfere na imagem que o catador faz de si. Para Migueles (2004), o trabalho com o lixo interfere tanto na identificação do catador com o seu trabalho como no reconhecimento da sociedade pelo trabalho desempenhado pelo catador.

Catar lixo é considerado por Barros, Sales e Nogueira (2002) uma atividade excludente pela própria natureza do tipo de trabalho. Entretanto, a mídia em geral, alguns estudiosos e instituições de diversos setores divulgam que a catação constitui uma possibilidade de inclusão social de uma parcela de trabalhadores.

Mas qual a qualidade dessa inclusão? Seria o fato de estar trabalhando, não importa em quê e como, garantia de inclusão social? $\mathrm{O}$ fato de conseguirem garantir meios para a sua sobrevivência e a de seus familiares seria sinônimo de inclusão? Seria de fato uma inclusão ou mais uma forma de exclusão transmutada em inclusão?

Sob o ponto de vista psicossocial, Miura (2004) afirma que tornar-se catador é sentido como fonte de dignidade e modo legítimo de obter renda. É uma atividade que faz do excluído um trabalhador inserido no mundo do trabalho, diferenciando-o do mendigo ou vadio.

Contudo, a inclusão desses catadores ocorre de forma perversa. Dessa forma, pode-se inferir que o catador de materiais recicláveis é incluído ao ter um trabalho, mas excluído pelo tipo de trabalho que realiza: trabalho precário, realizado em condições inadequadas, com alto grau de periculosidade e insalubridade, sem reconhecimento social, com riscos muitas vezes irreversíveis à saúde, com a ausência total de garantias trabalhistas.
Uma análise prematura da situação dos catadores de materiais recicláveis levaria a uma conclusão equivocada: a de que estariam incluídos socialmente. Isso porque por trás de formas aparentes de inclusão social, existem formas sutis de exclusão que conduzem à inclusão perversa.

$O$ fato dos catadores constarem na Classificação Brasileira de Ocupações - CBO - poderia ser um indicativo que apontasse para o resgate da dignidade desses trabalhadores, inserindo-os no âmbito das políticas públicas.

Porém, o que se observa é uma condição oposta, na qual o trabalho da catação é quase sempre desfavorável ao trabalhador. Conforme estudos nessa pesquisa, o trabalhador catador é exposto a riscos à saúde, a preconceitos sociais e à desregulamentação dos direitos trabalhistas, condições que são extremamente precárias, tanto na informalidade de trabalho, quanto na remuneração. Além disso, os catadores não têm acesso à educação e ao aprimoramento técnico.

Paradoxalmente, mesmo ocorrendo nas condições demonstradas, que são bastante adversas, a catação possibilita a sobrevivência de muitos trabalhadores, que se encontravam excluídos e sem alternativas para a subsistência. Lentamente, os catadores buscam se organizar em cooperativas e associações, visando melhores condições de trabalho.

As cooperativas de reciclagem de lixo são recentes no Brasil. Uma das pioneiras, de acordo com Magera (2003), é a Cooperativa dos Catadores Autônomos de Papel, Aparas e Materiais Reaproveitáveis - COOPAMARE -,fundada no ano de 1985, na cidade de Belo Horizonte.

Uma cooperativa de catadores pode desenvolver diferentes ações, visando enfrentar fatores que interferem no processo de negociação de materiais recicláveis, possibilitando competitividade através do aumento da oferta de materiais recicláveis num volume maior que garanta negociação de preços.

O IPT (2003) também destaca as seguintes vantagens da cooperativa: evitar depender de um único comprador; vender cargas "fechadas" por um preço médio; estocar - os materiais podem ser armazenados por período mais longos, se o galpão de triagem dispuser de espaço e houver capital de giro.

Ainda conforme o IPT (2003), o objetivo central de uma cooperativa de catadores de material reciclável é gerar oportunidades de trabalho e renda. Das vantagens econômicas advindas da organização em cooperativas de trabalho, o IPT apresenta o fato de os catadores conseguirem um valor mais alto pelo produto, pois ofertam produtos em melhores condições de limpeza e classificação e barateiam o transporte, prensando as cargas.

Esse Instituto chama a atenção para os indicativos de quantidade, qualidade e regularidade no fornecimen- 
to de matérias-primas como requisitos essenciais da produção industrial. Nesse sentido, os estudos do IPT (2003) apontam para a organização do trabalho dos catadores em cooperativas como elemento fundamental para se obter melhores condições para a venda direta e, conseqüentemente, a obtenção de melhores preços.

\section{Método}

Trata-se de uma pesquisa de caráter descritivo-exploratório. A coleta de dados foi realizada utilizando-se entrevistas semi-estruturadas com participantes que eram ligados a duas cooperativas de reciclagem localizadas em Goiânia. As categorias abordadas na entrevista se relacionavam: à identificação e a dados sóciodemográficos; à escolaridade; à profissão de catador e às relações de trabalho.

Participantes - optou-se por trabalhar com uma amostra de dez trabalhadores, escolhidos aleatoriamente, não contemplando crianças e adolescentes menores de 18 anos. Todos deveriam, necessariamente, estar ligados a uma das duas cooperativas de trabalhadores que coletavam materiais recicláveis em Goiânia, as únicas na época da coleta de dados.

Procedimentos - realizou-se algumas entrevistaspiloto do roteiro de entrevista com a finalidade de verificar a compreensão das perguntas pelos entrevistados, após os ajustes, os participantes foram entrevistados.

Dos 10 trabalhadores pesquisados, seis eram do sexo feminino e quatro do sexo masculino, com idades variando de 18 a 60. O estado civil dos participantes foi, predominantemente, o concubinato. A escolaridade dos participantes era, predominantemente, de semi-analfabetos ou com ensino fundamental completo.

As entrevistas foram realizadas de forma individual, com autorização expressa de cada participante, seguindo orientações técnicas do comitê de ética em pesquisa, e utilizou-se um gravador. Cada entrevista foi transcrita na íntegra, com autorização dos participantes, preservando-se o anonimato dos mesmos. Os dados coletados foram analisados segundo a análise de conteúdo de Bardin (1997), que objetiva analisar o conteúdo do discurso, levantando as categorias fundamentais do mesmo.

\section{Resultados}

Considerando os dados sócio-demográficos, levantouse que sete sujeitos eram provenientes de municípios localizados no interior do Estado de Goiás, provenientes da zona rural. Notou-se que a maior parte dos catadores teve pouco acesso à escola, sendo que sete não completaram a primeira fase do ensino fundamental. A baixa escolaridade dos catadores foi levantada em pesquisas anteriores, realizadas por Silva (2002) e Magera (2003), que correlacionaram escolaridade e trabalho. Para esses autores, a escolaridade é um fator que direciona para a exclusão do mercado formal de trabalho.
No discurso de alguns sujeitos, a formação escolar insuficiente foi considerada como um empecilho na busca de outro tipo de trabalho, como pode-se verificar no discurso do $\mathrm{S}^{1}$ e $\mathrm{S} 2$ :

Eu morava na roça né, e lá não tinha prazo para estuda, eu morava longe da cidade, agora que a gente ta precisando... agora que a gente ta sentindo falta do estudo. Qualquer coisa que a gente vai faze hoje tem que te estudo, pelo meno um estudo, pelo meno a quinta série para arruma um serviço mais ou menos. Mas agora. S1

Além dessa constatação, a baixa escolaridade também está associada à auto-imagem que os catadores fazem de sua profissão e posição social. Muitos catadores associam a falta de estudos à condição de ter que viver do trabalho de catação, o que para muitos representa humilhação e vergonha. Pode-se inferir que essa associação denota o preconceito e o descrédito que os próprios catadores têm em relação à profissão que exercem.

Eu penso assim que eu nessa profissão que eu tô eu acho eu não tenho um futuro pra frente né, porque eu só ganho mesmo pra cume e pra vesti e compra remédio né. Eu não tenho futuro, eu não quero isso pra os meu filhos né, jamais eu num quero que os meus filho vai puxar carrinho na rua. É por isso que eu dô os estudo pra eles pra eles ir pra frente, ter um futuro melhor, melhor do que eu né então eu espero é isso né. S2

Quanto ao fator idade, os dados revelaram uma predominância de sujeitos entre 30 e 60 anos. Segundo os entrevistados, a idade constitui-se em obstáculo para o re-ingresso no mercado formal de trabalho. De acordo com Castro (citado em Silva, 2003), a idade é um dos fatores que mais afetam a forma de participação no mercado de trabalho urbano formal, o qual, no Brasil, é mais favorável ao recrutamento de jovens. Já na catação, a idade não constitui fator excludente, pois uma das características dessa atividade é a ausência de exigências para o seu ingresso.

"Vai numa firma pra você vê, fala a idade, eles fala não você ta muito cabado não serve pra nóis não, nois qué é caboclo novo aqui” (S10).

Com relação à categoria profissão, os catadores tiveram sua profissão regulamentada em 2002, e sob o número 5192, são registrados na CBO - Classificação Brasileira de Ocupações. O reconhecimento da profissão de catador de material reciclável representou um importante passo na busca por reconhecimento de seus direitos. Ocorre que, desde essa época, os avanços em relação à formalização das relações de trabalho foram tímidos, e nota-se o predomínio da informalidade nas relações de trabalho.

Não há como ignorar que as condições em que os cata- 
dores desenvolvem seu trabalho são extremamente precárias. Isso porque são inúmeros os riscos à saúde existentes na atividade de catação no lixo, os catadores são desprovidos de garantias trabalhistas que os amparem, principalmente em condições de acidentes do trabalho, doenças, aposentadoria, décimo terceiro e seguro desemprego. Além disso, são mal remunerados, vítimas de preconceitos e não são reconhecidos.

Vale ressaltar que o trabalho com o lixo não tem uma única representação ou sentido, ou é dotado de características ruins ou de características boas. Ele abarca tanto aspectos positivos quanto negativos, por isso, a relação dos catadores com o lixo é ambígua, refletindo a dialética inclusão/exclusão, saúde/doença, orgulho/humilhação. $\mathrm{O}$ lixo, segundo Miura (2004), representa para os catadores seu meio de vida, a condição para garantir sua sobrevivência, a sua integração no mercado de trabalho, sem deixar de ter a conotação negativa construída socialmente em torno do lixo, ou seja, lixo é aquilo que é jogado fora, que gera asco, discriminação e preconceito. Essa ambigüidade que representa o trabalho com o lixo fica evidenciado no discurso de S4:

É um serviço ruim, mas é um serviço digno, eu tô fazendo um serviço digno, eu tô ganhando o meu dinheiro limpo, né. É um serviço sujo mas eu to ganhando meu dinheiro limpo, né. (S4)

Com relação à categoria relações de trabalho, verificase um reflexo da abertura econômica presenciada no país, a partir dos anos 1980, que possibilitou às empresas adotarem inovações tecnológicas e organizacionais que tivessem como um de seus efeitos a redução de postos de trabalho e, por conseqüência, a demissão de grande número de trabalhadores. Com o emprego formal diminuindo, ampliou-se a informalidade nas relações de trabalho. Portanto, outro aspecto relevante a ser considerado é que a maior parcela dos entrevistados, antes de se tornarem catadores, trabalhavam como assalariados no emprego formal.

A situação de desemprego aparece como elemento fundamental para o direcionamento para a atividade de catação, tendo em vista que essa se constitui em uma atividade alternativa para a obtenção de renda que garanta a sobrevivência do catador e de seus familiares.

O desemprego da época, a oportunidade de trabalho que era muito pouco, né, e a necessidade de ter minha tenda, de assistir minhas necessidade. (S4).

Eu tava precisando ganha dinheiro então quando a gente tá precisando a gente enfrenta qualquer trabalho. (S7).

Uma das características do trabalhador informal é a ausência de todos os direitos trabalhistas. Essa situação gera preocupação e sofrimento aos catadores, pois eles não contariam com nenhuma proteção trabalhista, caso fossem afastados por problemas de saúde e/ou acidentes de trabalho. Quanto à aposentadoria, também não se verificou nenhum tipo de contribuição. Esse desamparo foi percebido nos discursos dos catadores que não vislumbravam perspectivas futuras, conforme evidenciaram S4 e S5.

Aí isso daí deixa a gente triste porque a gente chega lá na idade de se aposentar cadê o direito não tem. Se eu tivesse você já pensou? Eu com 6 anos e fosse carteira assinada, era outra coisa. (S4)

Nada, não tem futuro nenhum. Porque o futuro da gente é no trabalho da gente, se o trabalho da gente não está dando resultado o futuro da gente também não vai dar em nada. Sempre é o que a minha esposa fala, você não ta pagando o INSS, não ta pagando nada, como é que a gente vamos faze daqui mais tempo. Quando você tiver mais veio ainda, porque cada vez a gente vai ficando só mais velho ainda. (S5)

Em relação a acidentes de trabalho e condições insalubres ligadas à saúde do trabalhador, especificamente, Porto, Juncá, Gonçalves e Filhote (2004) ressaltam que a forte carga física da catação, somada ao trato com o lixo, e a própria rotina de trabalho são fatores que predispõem a certos tipos de doenças associadas ao trabalho, entre elas: dores corporais, problemas osteo-articulares e hipertensão.

Embora não haja como negar a insalubridade existente na atividade de catação, um dado que chamou a atenção foi a baixa menção dos participantes a doenças relacionadas ao lixo ou a acidentes de trabalho associados à catação. Esse dado também foi verificado nas pesquisas de Porto et al. (2004) e Miura (2004).

Os participantes não consideravam cortes, perfurações e escoriações como acidentes de trabalho. Percebeu-se que, para eles, acidentes de trabalho eram aqueles que geravam situações críticas que impediam de ir ao trabalho.

Sobre esse assunto, Miura (2004) comenta que os catadores não parecem preocupados com os prejuízos provocados à saúde pelo trabalho, estes são suplantados pelo fato dessa atividade garantir sua subsistência e promover sua inserção social e profissional. Segundo a autora, as dores nas pernas, a intoxicação pelo lixo, os cortes, os arranhões, tudo isso pode ser curado, o que é mais dolorido do que tudo isso é a fome.

Porto et al. (2004) ressaltam que os catadores percebem o lixo como fonte de sobrevivência, a saúde como capacidade para o trabalho e, portanto, tendem a negar a relação direta entre o trabalho e problemas de saúde.

Acidente não tem não. Só assim acidente leve né, de se levar uma pancada, cortar um dedo (risos), levar um tropeção, machucar, cortar uma mão (S4). 
Quanto ao uso de equipamentos de proteção individual (os EPI's), verificou-se o uso em alguns catadores. A luva foi o EPI mais destacado, porém, mesmo com o uso desse equipamento, ainda aconteciam cortes e perfurações. Segundo S2

Mesmo com a luva, às vezes vem caco de vidro né, outra hora vem agulha vem uma coisa aí você pega assim apressada aí corta a luva às vezes corta a mão mas a gente trata na hora $(S 2)$.

Sobre a coleta de materiais recicláveis, alguns participantes apontaram para a dificuldade em encontrar alguns tipos de materiais, principalmente a lata de alumínio. $\mathrm{O}$ desaparecimento da lata de alumínio, especificamente dos lixos urbanos, se deu em decorrência de seu alto valor no mercado de reciclados, o que tornou esse material altamente disputado, inclusive por pessoas que não sobrevivem da catação.

Atualmente, o Brasil destaca-se entre os países que mais reciclam latas de alumínio. A reciclagem desse material, do ponto de vista da inclusão profissional dos catadores, é contraditória. Isso porque, se por um lado ocorrem ganhos ambientais com o aproveitamento de um grande número de latas de alumínio no processo de reciclagem, por outro lado, está sendo conseguida com uma participação cada vez menor dos catadores, pois é crescente o número de pessoas que não vivem da catação e que estão selecionando esse item para a venda. Sem essa matériaprima, muitos catadores estão vendo sua renda diminuir ainda mais. Miura (2004) afirma que os catadores conseguiram entrar no mercado numa época em que a reciclagem estava sendo valorizada preponderantemente por questões ambientais, mas, à medida que essa atividade se mostrou lucrativa, foram gradativamente sendo expulsos.

Isso fica bem evidenciado no discurso de S3:

O que compensa mais coletá é a latinha, você já vende rápido. A latinha ta vindo muito pouco né. As pessoas já catam pra lá mesmo, né, é muito pouco a latinha.

A organização do trabalho em cooperativas configurase em uma alternativa de fortalecimento dos catadores de materiais recicláveis na busca de melhores condições de trabalho. Migueles (2004) correlaciona o significado social do lixo, que é preponderantemente negativo, com os processos de formação da identidade e a motivação dos sujeitos para lidar com essa atividade. A autora conclui que o significado social do lixo influencia no sucesso da gestão das cooperativas, tendo em vista que os catadores-cooperados não investem em seu potencial profissional, pois não se identificam com a profissão que exercem.

Numa direção oposta, Miura (2004) comenta que, embora a catação ocorra em condições desfavoráveis e não altere a estrutura da desigualdade social, ela possibilita, mesmo que temporariamente, a inserção social. Segundo a autora, a organização em cooperativas possibilita uma condição de trabalho mais favorável, com estrutura física mais adequada e oportunidades de ganho maiores, tanto na perspectiva material como social:

Ser cooperado é a mesma coisa de ser, de ser um empresário, um comerciante [risos] mesmo que a sua renda seja pouca mas você sente um empresário. (S4)

\section{Discussão}

Pode-se considerar que os objetivos da pesquisa foram alcançados, uma vez que foi possível levantar dados acerca da percepção que os catadores de lixo têm de suas relações de trabalho e de sua profissão. A utilização de entrevistas também se mostrou adequada, uma vez que possibilitou levantar as categorias que compõem as representações dos participantes sobre o tema pesquisado.

A Revolução Industrial foi um marco para as questões ambientais, e o solo e o subsolo passaram a se constituir em grandes receptáculos para praticamente todos os resíduos sólidos gerados pela sociedade consumidora de produtos industrializados e, em larga medida, descartáveis. Atualmente, a geração e acúmulo de lixo se constituem como um dos problemas ambientais de extrema relevância e gravidade. Dentre as conseqüências provocadas por geração e acúmulo de lixo têm-se a escassez dos recursos naturais, a degradação ambiental e o esgotamento de espaço físico para o armazenamento dos resíduos produzidos.

Dentre as alternativas de tratamento para o lixo urbano, a reciclagem configura-se como importante elemento, pois possibilita o reaproveitamento de materiais descartados novamente ao circuito produtivo e traz benefícios ambientais através da economia de recursos naturais, energia e água. Além do inquestionável aspecto ambiental, a reciclagem possibilita ganhos sociais ao absorver no seu circuito produtivo os catadores de materiais recicláveis.

Esses trabalhadores desempenham um papel preponderante para o processo de reciclagem, pois, atualmente, o fruto de seu trabalho é ponto de partida para o abastecimento, com matérias-primas, das indústrias de reciclagem. Apesar disso, atividade é executada em condições extremamente precárias e informais de trabalho e remuneração, o que evidencia o caráter perverso da inclusão que essa atividade possibilita.

A dialética inclusão/exclusão permite compreender o conceito de inclusão como um processo, e, assim, possibilita a compreensão da inclusão social pela exclusão. É o que se observa ao analisar as relações de trabalho dos catadores de materiais recicláveis: excluídos do mercado de trabalho, os trabalhadores encontram na cata- 
ção a possibilidade de garantir sua sobrevivência, mesmo executando um trabalho desprovido de qualquer garantia trabalhista, e, a partir daí, sentem-se novamente incluídos.

Contudo, trata-se de uma inclusão perversa, pois como se pode verificar, com a lucratividade assegurada pelos processos de reciclagem, estes estão sendo realizados por pessoas de diferentes segmentos e até mesmo por organizações terceirizadas, o que conduz paulatinamente para nova exclusão dos catadores.

Trata-se de um tema relevante e atual, e seguramente não se esgotará em uma pesquisa, sugere-se que outras pesquisas sejam desenvolvidas aprofundando as formas de inclusão perversa e a alienação dos catadores de lixo.

Como conclusão, apresenta-se um questionamento: Por que não investir em políticas públicas que garantam a inserção social com qualidade de vida para esses trabalhadores? As cooperativas de trabalho configuram-se em estruturas organizacionais que podem possibilitar essa inclusão justa e de modo não perverso.

\section{Nota}

1. Adotou-se como sigla $\mathrm{S}$ para sujeito e $\mathrm{n}^{\circ}$ para codificar cada participante.

\section{Referências}

Antunes, R. (1995). Adeus ao trabalho? - Ensaio sobre as metamorfoses e a centralidade do mundo do trabalho. ( $6^{\mathrm{a}}$. ed.). Campinas, SP: Cortez.

Barros, V.A.; Sales M.M. \& Nogueira, M.L.M. (2002). Exclusão, favela e vergonha: uma interrogação ao trabalho. Em Goulart, Í.B. (Org.). Psicologia organizacional e do trabalho: teoria, pesquisa e temas correlatos. São Paulo: Casa do Psicólogo.

Bardin, L. (1995). Análise de Conteúdo. (L. Reto e Pinheiro, trad.). Lisboa, Portugal.

Borges, A.F. \& Goulart, I. (Eds.). (2002). Psicologia organizacional e do trabalho: teoria, pesquisa e temas correlatos. São Paulo: Casa do Psicólogo.

Birbeck, C. (1978). Self-employed proletarians in an informal factory: the case of cali's garbage dump. World Development 6 (9-10), 1173-1185.

Carmo, M.S. (2005). A semântica "negativa" do lixo como fator "positivo" à sobrevivência da Catação-Estudo de caso sobre a associação dos recicladores do Rio de Janeiro . Em Encontro Nacional da Associação Nacional de Pós-graduação em Pesquisa em Administração. ENANPAD, Brasília - DF.

Codo,W. (1993). Indivíduo, trabalho e sofrimento: uma abordagem interdisciplinar. Petrópolis, RJ: Vozes.

Dejours, C. (1994). A loucura do trabalho: contribuições da escola dejouriana à análise da relação prazer, sofrimento e trabalho. ( $2^{\mathrm{a}}$ ed.). São Paulo, SP: Atlas.

Dejours, C. (1999). A banalização da injustiça social. (4a ed.). Rio de Janeiro, RJ: Editora da FGV.

Freitas, M.V.O.(2005). Entre ruas, lembranças e palavras: a trajetória dos catadores de papel em Belo Horizonte. Belo Horizonte: PUC Minas.

Guareshi, P.A. (1999). Pressupostos psicossociais da exclusão: competitividade e culpabilização. Em Sawaia, B.B.(Org.), As artimanhas da Exclusão: Análise Psicossocial e Ética da Desigualdade Social. Petrópolis, RJ: Vozes.
Heloani, R. (2003). Gestão e Organização no Capitalismo Globalizado. São Paulo: Atlas.

Instituto de Pesquisa Tecnológica-IPT (2003). Cooperativa de catadores de materiais recicláveis: guia para implantação. São Paulo: SEBRAE.

Leal, A.C.; Júnior, A.T.; Alves, N.; Gonçalves, M.A. \& Dibiezo, E.P. (2002). A reinserção do lixo na sociedade do capital: uma contribuição ao entendimento do trabalho na catação e na reciclagem. Revista Terra Livre, São Paulo, 18(19), 177-190, jul/dez.

Magera, M. (2003). Os empresários do lixo: um paradoxo da modernidade. Campinas, SP: Átomo.

Marx, K. (1978). O capital, Livro I, capítulo VI (inédito). São Paulo: Editora da USP - Ciências Humanas.

Marinho, M.C.N. (2005). As transformações no mundo do trabalho e suas implicações na formação do executivo. Universidade Católica de Goiás, Dissertação de Mestrado não publicada, Mestrado em Psicologia. Goiânia, GO.

Migueles, C. P. (2004). Significado do lixo e ação econômica - a semântica do lixo e o trabalho dos catadores do Rio de Janeiro. Em Encontro Nacional da Associação Nacional de Pós-graduação em Pesquisa em Administração - ENANPAD, Curitiba PR.

Mattoso, J. (1999). O Brasil desempregado: Como foram destruídos mais de 3 milhões de empregos nos anos 90. São Paulo: ABRAMO.

Miura, P. C. O. (2004). Tornar-se catador: uma análise psicossocial. Dissertação de mestrado não publicada, Mestrado em Psicologia Social, orientadora Dra. Bader Sawaia, Pontifícia Universidade Católica de São Paulo. São Paulo, SP.

Noronha, E. G. (2003). Informal, ilegal, injusto: percepções do mercado de trabalho no Brasil , Revista Brasileira de Ciências Sociais, 18(153), 111-129.

Piccinini, V. C. (2004). Cooperativas de trabalho de Porto Alegre e flexibilização do trabalho. Sociologias, 6 (12), 68-105.

Porto, M. F. S.; Juncá, D. C. M.; Gonçalves, R. S \& Filhote, M.I. F. (2004). Lixo, trabalho e saúde: um estudo de caso com catadores em um aterro metropolitano no Rio de Janeiro, Brasil. Caderno Saúde Pública, Rio de Janeiro, 20 (6), 1503-1514.

Sawaia, B. (Ed.)(1999). As artimanhas da Exclusão: Análise Psicossocial e Ética da Desigualdade Social, ( ${ }^{\text {a }}$ ed.). Petrópolis, RJ: Vozes.

Silva, A. C. G. (2002). Catadores de lixo: aspectos sócio-ambiental da atividade desenvolvida no lixão municipal de Corumbá, Mato Grosso do Sul. Universidade de Brasília, Dissertação de Mestrado não publicada, Centro de Desenvolvimento Sustentável. Campo Grande, MS.

Souto de Oliveira, J. S. (2004). Mutações no Mundo do trabalho: o (triste) espetáculo da informalização. Revista Democracia Viva, l(1), 8-12

Sposati, A. Prefácio, Em Sawaia, B. B. Namura, M. R. (Orgs.) Dialética exclusão/inclusão: reflexões metodológicas e relatos de pesquisa na perspectiva da psiclolgia social crítica. Taubaté, São Paulo: Cabral Editora Universitária, 2002.

Viana, N. (2000). Catadores de lixo: renda familiar, consumo e trabalho precoce. Revista Estudos da Universidade Católica de Goiás. 27(3), 407-691.

Wanderley, M. B. (1999). Refletindo sobre a noção de exclusão. Em Sawaia, B. (Ed.) As artimanhas da Exclusão: Análise Psicossocial e Ética da Desigualdade Social, (4ª ed.). Petrópolis, RJ: Vozes. 
Luiza Ferreira de Rezende Medeiros é mestre em Psicologia pela Universidade Católica de Goiás, professora da Faculdade Cambury e pesquisadora colaboradora da Universidade Católica de Goiás luiza502@bol.com.br

Kátia Barbosa Macedo é doutora em Psicologia Social pela PUC-SP, professora titular e pesquisadora da Universidade Católica de Goiás. Endereço: Rua Sevilha, Q184, 1.17, Condomínio Sevilha, Casa 2, Jardim Europa, Goiânia-GO. CEP 74330570.

\section{Catador de material reciclável: uma profissão} para além da sobrevivência?

Luiza Ferreira de Rezende Medeiros \& Kátia Barbosa Macedo Recebido: 10/12/2005

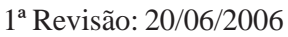

Aceite final: 20/06/2006 